\title{
“CRÍTICA” / DIAGNÓSTICO / 2015
}

Poucos colegas, se há algum, no pequeno mas multívoco mundo internacional de nossa profissão acadêmica, têm seguido e comentado as mudanças continuadas da "Crítica Literária" com tanta circunspecção, complexidade analítica, transparência e sobriedade (às vezes irônica) como meu amigo José Luis Jobim. Paradoxalmente, de algum modo esta visão panorâmica se tornou seu foco especializado e sua forma de identidade intelectual. Tendo em vista o quão presente e simplesmente útil esse livro permaneceu, fiquei surpreso de perceber que treze anos já se passaram desde que Jobim me deu a oportunidade bem-vinda de escrever uma breve introdução para Formas da Teoria - Sentidos, Conceitos, Políticas e Campos de Força nos Estudos Literários.

Meu ponto de ênfase foi, além de descrever o estilo de Jobim, localizar com precisão, através de sua perspectiva, 2002 como um primeiro momento em que quase um século de abundante produção e incessante importação de "teorias" em nossa disciplina tinha chegado, então, a uma surpreendente parada. Mas, enquanto naquele momento era possível imaginar que esse movimento singularmente dinâmico dentro das "Humanidades e Artes" tinha diminuído muito pouco, talvez em um congestionamento temporário, nossa retrospectiva hoje, sem muita controvérsia, vê o início do século XXI como um tempo de transição. A "era da teoria", não há dúvida, não recomeçou, e em vez de reclamarmos ou nos flagelarmos por isso, aprendemos a apreciar uma pletora de novas questôes e gostos, possivelmente junto com o desaparecimento da intensidade e pressão que costumavam acompanhar a obrigação de estar a par dos novos "paradigmas" a cada ano. Enquanto isso, acostumamo-nos ao hábito de reivindicar o surgimento de "viradas" em todos os lugares, como se esse sucessor mais fraco do conceito de "mudança de paradigma" pudesse e tivesse que manter vivo um passado sem o qual conseguimos viver surpreendentemente bem.

Se alguma coisa é confusa nesse lado mais bucólico (e principalmente menos passional), é a dificuldade que temos em encontrar um conceito abrangente para o presente mais recente nos "Estudos literários". Mesmo se fosse possível, como argumentei ${ }^{1}$, explicar tais transformaçôes como uma pequena parte dos efeitos decorrentes de uma nova constelação na construção social do tempo que modela nossas condiçóes de experiência e, através delas, nosso pensamento, isso de modo algum excluiria a possibilidade de tornar

${ }^{1}$ Above all in Our Broad Present and After 1945. 
centrífugo nosso oikos intelectual e profissional anteriormente coerente. Esse é o caso e será a premissa do breve exercício em que, espero, Jobim me acompanhará, de modo que, mais tarde ou o mais breve possível, possamos trocar impressões pessoalmente e face-a-face, no Rio ou em Stanford. Quais são os elementos e observaçóes que valem a pena registrar no estado centrífugo dos "Estudos literários" hoje? Essa é a questão por trás do meu retrato rápido com intençấo de diagnóstico?

Continuando a ser um "fetichista decimal" - rótulo que há muitos anos atrás meu amigo alemão, Gert Mattenklott, recentemente falecido, atribuiu ao meu modo pedestre de descrição -, contabilizo seis exemplos nesse diagnóstico. O primeiro que desejo mencionar mostra muito claramente o impacto de uma mudança na construção social do tempo, em uma linguagem mais familiar e provavelmente mais precisa; ele pode derivar do que identifico como um processo em que a "visáo de mundo histórica", nos termos em que emergiu no final do século dezoito e início do dezenove, está desaparecendo agora. Continuamos a retornar ao passado para editar e contextualizar textos. Algumas vezes, penso, devido aos novos recursos digitais, fazemos isso com maior precisão do que jamais foi feito, e, alguns de nós, entre os quais meu colega de Stanford Franco Moretti, usam os poderes de computaçáo dos mesmos artefatos eletrônicos para sintetizar uma quantidade de detalhes sem precedente em uma nova e mais "remota" visão. Mas nenhum desses projetos alega que pode fundamentar ou pelo menos sugerir qualquer prognóstico ou especulação em relação ao futuro, como gostavam nossos predecessores desde o tempo de Hegel. Junto com esses pressupostos, muito naturalmente, desapareceu a questão anteriormente central sobre quais poderiam ser as chances de ver o futuro desvelado pela história da literatura.

Isso pode ter a ver com essa nossa nova modéstia em nossas abordagens do passado e com uma tendência crescente a incluir o componente somático da existência humana, "como se" fosse um manuscrito ou "como se" fosse uma performance oral; trata-se de uma premissa anteriormente pré-consciente que formata o processo e, com isso, o resultado de nosso trabalho. Essa própria preocupação também explica as referências frequentes a um "Renascimento da Filologia" como o que tem sido mal compreendido. Diferente da "Filologia" no sentido tradicional (e ainda válido) de "curadoria de texto", a nova - e frequentemente muito vaga - camada de consciência sobre a mídia nos estudos literários tem um potencial futuro de mudar a camada programática de autocompreensão do nosso trabalho.

Todas as mudanças mencionadas até agora (e outras) podem ter 
contribuído para a impressão de que a noção de "literatura" parece viável de novo. O agora famoso ensaio de Michel Foucault (quase um manifesto) sobre a necessidade de uma historicização radical (como se gostava de dizer então) dos conceitos mais básicos na Crítica Literária, como "texto", "gênero", "leitor", por exemplo, e - acima de tudo, no ensaio de Foucault - "autor" (mas também o conceito de "literatura", obviamente), faz quase 50 anos. Em reação contra essa promessa de diferenciação, uma tendência logo surgiu para substituir, em muitos contextos acadêmicos diferentes, o conceito de "literatura" (como demasiado específico, historicamente) pelo de "cultura" que também parecia aberto o suficiente para a conclusão de novos objetos de interesse, não estritamente "literários", no espaço dos "Estudos Literários". O que veio a seguir foi, como sabemos, a dominância de curta duração dos "Estudos Culturais" como padrăo disciplinar. Hoje, pelo menos no mundo acadêmico norte-americano, o conceito de "Literatura" tem de retornar ao viável - embora os colegas agora tendam a evitar dar-lhe uma definição meta-histórica ou transcultural, cuja impossibilidade de concretização tinha sido um insight do final do século XIX. Em vez de parecer muito abstrato e claro, o conceito de "Literatura" parece conter uma conotação de concretude ou presença que alguns de nós (incluindo eu) gostam de associar com Realismo epistemológico (o oposto do Construtivismo ubíquo e, portanto, cada vez mais banal) que desejávamos, plenamente conscientes de sua impossibilidade. Talvez esse retorno - muito surpreendente, retrospectivamente - do conceito de "Literatura" seja o contexto em que uma nova proximidade entre a Crítica Literária e a produçáo literária deva ser mencionada, talvez mesmo uma mudança na proporção demográfica entre escrever e ler, em sentido amplo (a alternativa para esse tópico poderia ter sido meu segundo ponto, isto é, a nova ênfase na leitura estética). Pelo menos nas universidades americanas não se pode ignorar que, tanto em nível de graduação, quanto de pós-graduação, há um número crescente de alunos que optam pelo lado "prático" com as disciplinas das Humanidades: pelo Conservatório em vez da Musicologia; pela Oficina de Arte em vez da História da Arte; e pela Escrita Criativa [Creative Writing] em vez da Teoria Literária ou da História Literária. $\mathrm{Na}$ minha própria perspectiva (confessadamente local), este desenrolar converge com a impressão de que em uma de cada duas casas de nossa vizinhança há um novo romance surgindo - aparentemente sem muita preocupação sobre se tantos novos livros potenciais encontrarão leitores ou mesmo um mercado (o que pode ser um ponto positivo).

Aqueles de nós que continuam a ler (além de escrever, éóbvio) mudaram muito naturalmente - e sem argumentos complicados teoricamente - para 
uma seleção de textos, tanto históricos quanto contemporâneos, que se poderia chamar de "comparativos" no contexto acadêmico, e de "World Literature" em contextos menos ambiciosos.

"World Literature" como uma nova tendência crítica, eis minha quinta observação, apenas afirma o óbvio, isto é, que, em uma cultura que virou "global" (em um sentido bem preciso) através da comunicação eletrônica, é improvável, para não dizer impensável, que leitores de literatura - de fato, leitores de qualquer coisa - continuem a manter-se nas fronteiras nacionais do "cânon" ao selecionarem seu material de leitura. Isso explica o efeito acadêmico colateral de que a "Literatura Comparada", mais do que qualquer literatura nacional "estrangeira", é a escolha de estudantes hoje que querem envolver-se com o texto literário na graduação ou no doutorado. Âs vezes, sinto (ou temo?) que os Estudos Literários reagiram com uma superprodução de teoria e referências históricas (quando deixaremos de ver o uso da palavra "Weltliteratur" por Goethe mencionado com um gesto orgulhoso de erudição?).

Indo adiante rapidamente, para evitar quaisquer contribuiçôes involuntárias a essa superprodução acadêmica e também concluindo minha lista de diagnósticos, "World Literature" como um contexto natural (isto é, não acadêmico) de nossas operaçôes acadêmicas tem, é claro, mudado irreversivelmente o status de contribuiçôes à Crítica Literária (entre outras disciplinas, obviamente), de contribuiçóes que não vêm de alguns países europeus e dos países norte-americanos, externamente e internamente. Situações de assimetria e casos de injustiça acadêmica, é óbvio, continuam infelizmente a existir, mas sinto que ninguém pode negar que a produção crítica do Brasil, por exemplo, junto com a substância (sim, quero dizer "substância") da literatura e cultura brasileiras, encontram mais ressonância internacional do que tinham, digamos, há dez ou vinte anos atrás. É desnecessário (e, portanto, banal) dizer que há muito espaço para melhorar. Por outro lado (o lado mais local), essa mesma mudança significativa teve o efeito benéfico de diminuir o tom (náo o entusiasmo) de críticos, ao falarem sobre "suas" literaturas e culturas nacionais. A ambição ("romântica", no sentido histórico) de sempre tentar provar que os textos do cânon nacional eram os itens-chave "incomparavelmente valiosos e até então injustamente negligenciados" para um novo cânon a ser criado foi substituída por uma atitude de confiança, orgulho não atenuado e sobriedade comparativa.

Meu amigo Jobim, como eu disse no início desse breve exercício de diagnóstico, tem sido um predecessor enfático não-messiânico exatamente de tal atitude cultural e estilo intelectual. De certo modo, este já era o meu 
ponto naquela introdução ao seu livro Formas da Teoria - mas, há treze anos, Jobim parecia um agradável excêntrico, em vez de um precursor, porque ninguém poderia ter antecipado plenamente a mudança de posiçóes na orquestra internacional da Crítica Literária (se é que um leitor da sobriedade e ironia de Jobim pode usar tal metáfora pesada). E é exatamente o que quero dizer, quando afirmo que "não poderíamos ter antecipado o que ocorre agora". Naquela época, a maioria de nós presumia e teria reivindicado que poderia, mas, agora, prevalece a impressão de que perdemos tal otimismo, o que me traz de volta a meu ponto inicial sobre as premissas profundamente transformadas com as quais observamos o passado agora um passado remoto e um passado recente. Esta, obviamente, é a razão pela qual paro aqui - em vez de especular sobre o futuro (e talvez sobre o fim) da Crítica Literária.

Hans Ulrich Gumbrecht (Stanford University) 